\title{
Parafalcine Chondrosarcoma: Unusual Localization for a Classic Variant
}

\author{
Harish Naik ${ }^{1}$ Vernon Velho ${ }^{1}$ Amrita Guha \\ ${ }^{1}$ Department of Neurosurgery, J. J. Group of Hospitals and Grant \\ Medical College, Mumbai, Maharashtra, India \\ 2Department of Radiology, Tata Memorial Centre, Mumbai, \\ Maharashtra, India
}

Address for correspondence Harish Naik, MCh, Department of Neurosurgery, J. J. Group of Hospitals and Grant Medical College, Mumbai 400008, Maharashtra, India (e-mail: haryadoc@gmail.com).
Indian J Neurosurg 2019;8:81-85

Primary intracranial chondrosarcoma is an extremely rare malignant tumor of the central nervous system, which accounts for less than $0.16 \%$ of all primary intracranial tumors. ${ }^{1}$ Most are located at the skull base, where they are thought to arise from cartilage of the synchondroses. Less commonly, chondroid tumors arise from the choroid plexus, dura mater, or brain parenchyma. Histologically, three variants of chondrosarcoma have been described: myxoid, mesenchymal, and classic chondrosarcoma. Since the first description of intracranial chondrosarcoma by Mott in 1899, only 53 cases chondrosarcomas arising above the skull base have been reported and most of these are of the highly malignant mesenchymal variant. ${ }^{1-12}$ Only 12 cases of classic variant chondrosarcomas have been reported in the falcine/parafalcine location (- Table 1). ${ }^{2-12}$ The authors report one more case of classic chondrosarcoma arising in such an unusual location.

\section{Case Report}

A 30-year-old woman presented with history of headache and vomiting associated with episodes of giddiness of 5 -month duration. She also noticed clumsiness of her right hand. Clinical examination revealed subtle pyramidal signs in her right upper limb. Magnetic resonance imaging (MRI) of the brain revealed an extra-axial lobulated posterior parafalcine lesion. The lesion was predominantly composed of components that was hypointense on T1-and hyperintense on T2-weighted images ( - Fig. 1A). The lesion showed mild, heterogeneous contrast enhancement $(-$ Fig. 1B). She underwent a left parieto-occipital craniotomy and total excision of the lesion. The lesion was hard lobulated, grayish colored, and moderately vascular. Histologic examination of excised lesion revealed lobules of cartilage containing atypical chondrocytes consistent with low-grade chondrosarcoma (grade I). The tumor lobules were large, irregular with thin intervening minimal fibrous stroma. There was no necrosis or significant atypia (-Fig. 2). S-100 protein (1:300; Dako), vimentin, and epithelial membrane antigen (EMA, 1:100, Dako) were used for immunocytochemical study of the specimen. The neoplastic chondrocytes showed both cytoplasmic and nuclear staining for S-100 protein and vimentin, but not for EMA. The diagnosis of well-differentiated chondrosarcoma was made.

Follow-up MRI at 12 months after surgery showed no residual or recurrent lesion (-Fig. $\mathbf{3}$ ).

\section{Discussion}

Intracranial chondrosarcoma is a rare malignant cartilaginous tumor that was first reported by Mott in 1899. They can be associated with Maffucci's and Olliers' syndrome. They frequently arise at the skull base from the undifferentiated embryonic cells of the cartilaginous synchondroses.

Intracranial chondrosarcomas of dural origin are very rare, and only 53 cases have been reported till date. ${ }^{1-12}$ Though majority of the skull-base chondrosarcomas are of classic variant (> 80\%), dural-based chondrosarcomas are predominantly of mesenchymal variant (60\%). Of the 25 falcine and parasagittal chondrosarcomas reported so far, only 12 cases were of classic variant (- Table $\mathbf{1}){ }^{1-12}$ The remaining cases were predominantly mesenchymal with only one myxoid variant. There was a strong female preponderance. ${ }^{1-12}$ In this article, the authors report a case of classic variant of chondrosarcoma that was dural based and parafalcine in location.

According to review of chondrosarcomas by Korten et al, ${ }^{13}$ $37 \%$ of tumors were located in the petrous bone, whereas $23 \%$ were found in the occipital bone and clivus; $20 \%$ in the sphenoid bone; and $14 \%$ in the frontal, ethmoidal, and parietal bones. In only $6 \%$ of cases was the primary location in dural tissue, which normally does not contain cartilage.

Generally, patients present with an extensive history of headaches and symptoms associated with increased intracranial pressure. Cranial nerve palsies or hemiparesis may also occur with such lesions, as can dizziness, tinnitus, sensory disturbances of the face, and decreased visual acuity.

Several theories regarding the histogenesis of dural derived cartilaginous lesions have been proposed. One theory suggests that the meninges contain primitive multipotential mesenchymal cells that potentially could give rise to chondrosarcomas. ${ }^{12}$ Other theory suggest that meningeal fibroblasts received

February 27, 2018

DOI https://doi.org/

$10.1055 / \mathrm{s}-0038-1676170$

accepted after revision

April 17, 2018

published online

March 27, 2019
C2019 Neurological Surgeons'

Society of India
License terms

() (1) $\Theta \circledast$ 
Table 1 Clinical characteristics of all the 12 cases including our case of classic variant of extraskeletal chondrosarcomas at falx and parasagittal locations

\begin{tabular}{|c|c|c|c|c|c|c|c|}
\hline Year & Article & $\begin{array}{l}\text { Age/ } \\
\text { sex }\end{array}$ & Location & Pathology & Follow-up & Recurrence & Alive/dead \\
\hline 1978 & $\begin{array}{l}\text { Alvira and } \\
\text { McLaurin }\end{array}$ & $21 / F$ & $\begin{array}{l}\text { Left frontal subdural } \\
\text { and interhemispheric }\end{array}$ & $\begin{array}{l}\text { Low-grade } \\
\text { chondrosarcoma }\end{array}$ & No follow-up & $\begin{array}{l}\text { No } \\
\text { follow-up }\end{array}$ & No follow-up \\
\hline 1985 & Cybulski et $\mathrm{al}^{3}$ & $58 / \mathrm{M}$ & Anterior falx & $\begin{array}{l}\text { Low-grade } \\
\text { chondrosarcoma }\end{array}$ & $18 \mathrm{mo}$ & No & Alive \\
\hline 1998 & Gerszten et al ${ }^{4}$ & $12 / \mathrm{F}$ & Falx & $\begin{array}{l}\text { Low-grade } \\
\text { chondrosarcoma }\end{array}$ & $9 \mathrm{mo}$ & No & Alive \\
\hline 1998 & $\begin{array}{l}\text { Forbes and } \\
\text { Eljamel }^{5}\end{array}$ & $19 / F$ & Anterior falx & $\begin{array}{l}\text { Nonmes- } \\
\text { enchymal } \\
\text { chondrosarcoma }\end{array}$ & $2 y$ & No & Alive \\
\hline 2001 & Oruckaptan et al ${ }^{6}$ & $56 / F$ & Anterior falx & $\begin{array}{l}\text { Low-grade } \\
\text { classic } \\
\text { chondrosarcoma }\end{array}$ & $3 y$ & No & Alive \\
\hline 2003 & Kothary et al ${ }^{7}$ & $28 / F$ & $\begin{array}{l}\text { Frontoparietal } \\
\text { parasagittal }\end{array}$ & $\begin{array}{l}\text { Classic } \\
\text { chondrosarcoma }\end{array}$ & No follow-up & $\begin{array}{l}\text { No } \\
\text { follow-up }\end{array}$ & No follow-up \\
\hline 2005 & Tosaka et al ${ }^{8}$ & $18 / \mathrm{F}$ & Frontal parasagittal & $\begin{array}{l}\text { Low-grade } \\
\text { chondrosarcoma }\end{array}$ & No follow-up & $\begin{array}{l}\text { No } \\
\text { follow-up }\end{array}$ & No follow-up \\
\hline 2008 & $\begin{array}{l}\text { Kathiravel and } \\
\text { Finnis }{ }^{9}\end{array}$ & $32 / \mathrm{F}$ & $\begin{array}{l}\text { Left Frontoparietal } \\
\text { parasagittal }\end{array}$ & $\begin{array}{l}\text { Classic } \\
\text { chondrosarcoma }\end{array}$ & $15 \mathrm{mo}$ & No & Alive \\
\hline 2009 & Boccardo et $a^{10}$ & $32 / F$ & Anterior falx & $\begin{array}{l}\text { Low-grade } \\
\text { chondrosarcoma }\end{array}$ & NA & NA & NA \\
\hline 2009 & Güneş et al ${ }^{1}$ & $25 / M$ & Posterior falx & $\begin{array}{l}\text { Low-grade } \\
\text { chondrosarcoma }\end{array}$ & No follow-up & $\begin{array}{l}\text { No } \\
\text { follow-up }\end{array}$ & No follow-up \\
\hline 2011 & Krishnan et al ${ }^{12}$ & $23 / F$ & Anterior falx & $\begin{array}{l}\text { Grade I classic } \\
\text { chondrosarcoma }\end{array}$ & $16 \mathrm{mo}$ & No & Alive \\
\hline 2011 & Krishnan et al ${ }^{12}$ & $19 / M$ & $\begin{array}{l}\text { Right frontal } \\
\text { parasagittal }\end{array}$ & $\begin{array}{l}\text { Grade I classic } \\
\text { chondrosarcoma }\end{array}$ & $12 \mathrm{mo}$ & No & Alive \\
\hline 2018 & Present case & $30 / F$ & $\begin{array}{l}\text { Left parieto-posteri- } \\
\text { or parafalcine }\end{array}$ & $\begin{array}{l}\text { Grade I classic } \\
\text { chondrosarcoma }\end{array}$ & $12 \mathrm{mo}$ & No & Alive \\
\hline
\end{tabular}

Adapted from Krishnan et al. ${ }^{12}$

located in the undersurface of the dura and arachnoid were the origin of such tumors. ${ }^{13}$ Pluripotential mesenchymal cells of the meninges along the falx cerebri, tentorium, and cerebral convexity as well as the skull base occasionally act as precursor cells to these tumors. The rare intraparenchymal tumors are thought to arise from the pia-arachnoid cells of the Virchow-Robin spaces of intracerebral vessels. ${ }^{3,6}$

Three histopathologic variants of intracranial chondrosarcomas have been described: classic (well-differentiated), myxoid (intermediate), and mesenchymal (undifferentiated). Most chondrosarcomas arising above the skull base are of the mesenchymal subtype. ${ }^{13}$ Though mesenchymal chondrosarcomas occur mainly in the younger patients (between 10 and 30 years of age), grade I classic chondrosarcomas have no clear age preference. ${ }^{13}$ The tumor in this case exhibited classic features. Korten et al ${ }^{13}$ reviewed 192 cases of chondrosarcoma and reported that, in general, the mesenchymal type is malignant and occasionally spreads to distant areas, whereas the classic subtype is the most benign of the three subtypes.

Histopathologically, classic variant shows less prominent cellular stroma with predominant cartilaginous lobules with pleomorphic cartilage cells. Classic variant has three histological grades: grades I, II, and III. Grade I tumors resemble benign cartilaginous tumors, whereas grades II and III tumors are more cellular and exhibit more mitoses and less chondroid matrix. Mesenchymal chondrosarcomas have a biphasic pattern with undifferentiated mesenchymal cells among scattered islands of well-defined cartilage. Myxoid chondrosarcomas are intermediate-grade lesions that can be differentiated histologically by the presence of mucinous supporting stroma. ${ }^{13}$

On immunologic examination, chondrosarcomas usually exhibit significant positivity for S-100 and vimentin, whereas only scattered proliferating cells exhibit positivity for the proliferative marker, $\mathrm{K}_{\mathrm{i}}-67$. These features differentiate chondrosarcoma from meningioma, hemangiopericytoma, metastasis, and vascular malformations.

On imaging, these lesions are often mistaken as meningiomas due to their extra-axial location. Computed tomographic (CT) scan usually reveals an isodense/hyperdense mass with heterogeneous enhancement and varying degrees of calcification in patients with chondrosarcomas. ${ }^{13}$

On MRI, they are typically hyperintense on T2-weighted and hypointense on T1-weighted images. Variable shortening of T1 and T2 relaxation times due to scattered mature cartilage cells makes them heterogenous. On postcontrast study, classic variant shows a "honeycomb" pattern of enhancement 

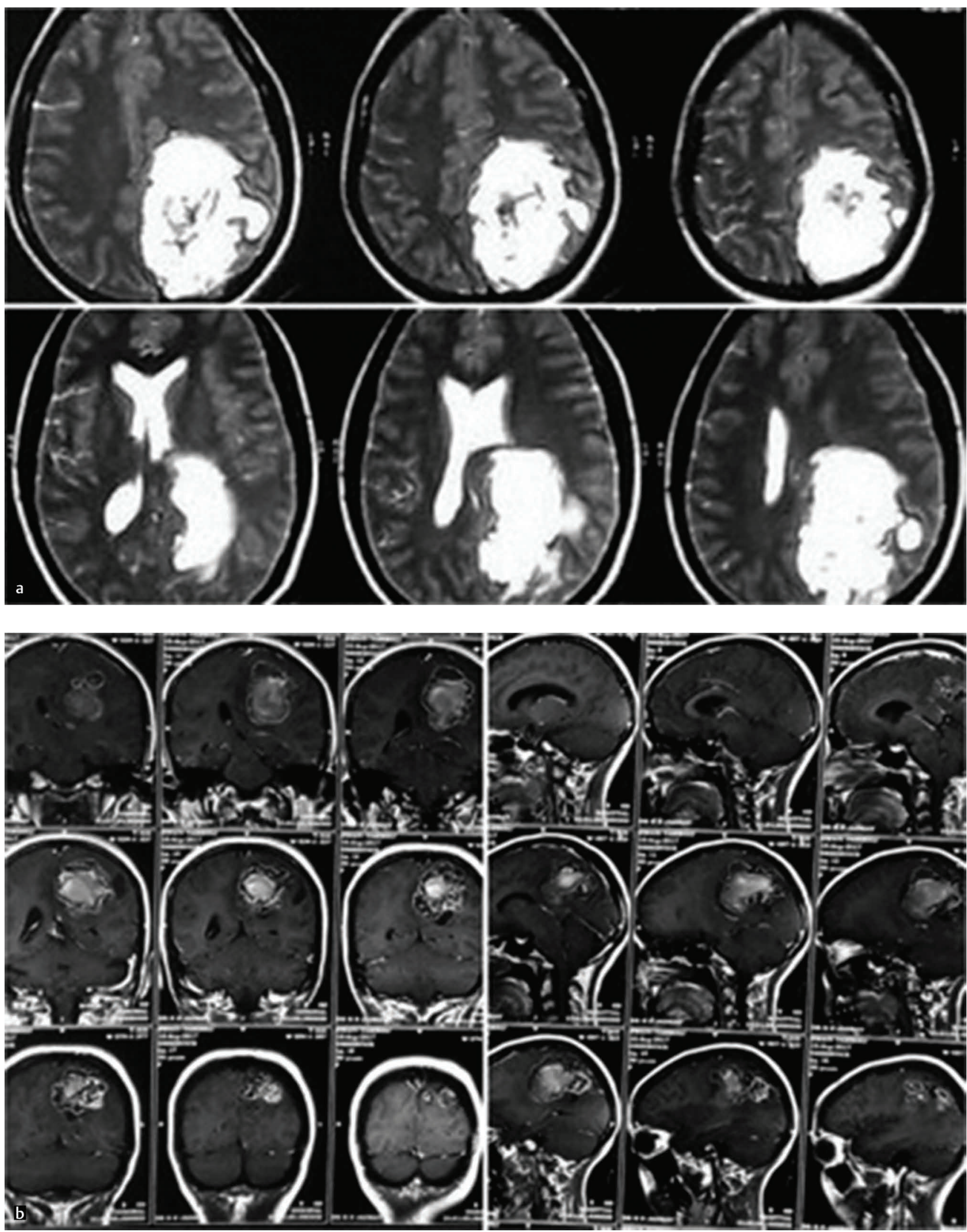

Fig. 1 (A) Magnetic resonance images showing the lesion in left parieto posterior parafalcine location that was predominantly composed of components that was hyperintense on T2-weighted and hypointense on T1-weighted sequences. (B) Postcontrast T1-weighted coronal and saggital magnetic resonance images showing heterogeneous contrast enhancement resembling honeycomb pattern of enhancement seen in classic variant of chondrosarcomas. 
whereas mesenchymal variant shows homogenous enhancement. Brighter signal on T2-weighted images and absence of dural tail differentiate them from meningiomas.,7 The MRI findings in this case was similar to those described in most prior reports.

Gross total resection would be the mainstay of treatment as recurrences and metastases are rare in the dural classic

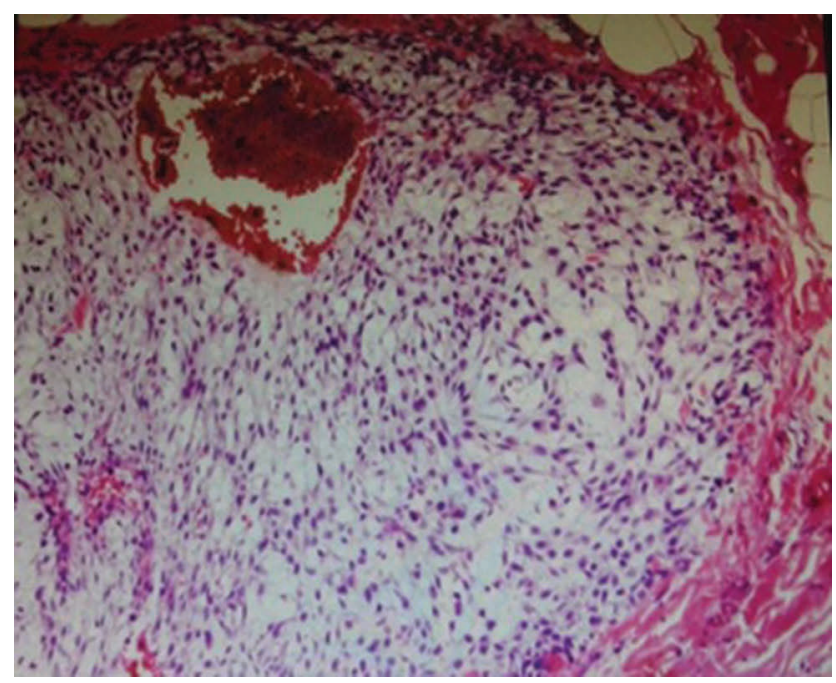

Fig. 2 Histologic examination of excised lesion revealed lobules of cartilage containing atypical chondrocytes consistent with low-grade chondrosarcoma (grade I). The tumor lobules were large, irregular with thin intervening minimal fibrous stroma. There was no necrosis or significant atypia. variant. Mesenchymal and myxoid chondrosarcomas have significantly higher recurrence rates than the classic variants, even after gross total excision. An infrequent tendency to distant metastasis is another indicator of poor outcome in these variants. ${ }^{12,13}$ This aggressive behavior pattern has led many authors to consider adjuvant radiotherapy even after the successful radical resection of mesenchymal and myxoid chondrosarcomas. In contrast, if a complete resection is achieved, limiting treatment to surgery alone is a frequent therapeutic strategy for classic chondrosarcomas.

On review of the literature, the authors found there were no recurrences for dural-based classic chondrosarcomas after gross resection (the maximum follow-up period noted was 6 years). ${ }^{1-12}$ High-dose photon and/or proton beam therapy, which both have acceptable side effects, have been used for residual skull base chondrosarcomas and seem to provide superior results to conventional radiation techniques. ${ }^{13}$

In this case, the treatment was limited to surgery alone as the tumor exhibited good dissection margins from the surrounding tissue, and hence total resection was achieved. The patient subsequently exhibited a favorable prognosis after surgery, and there was no recurrence at 12 months of follow-up.

\section{Conclusion}

Chondrosarcomas are rare cartilaginous tumors of the CNS and are not limited to the skull base even in classic variants. Because of its rarity and similar imaging findings with
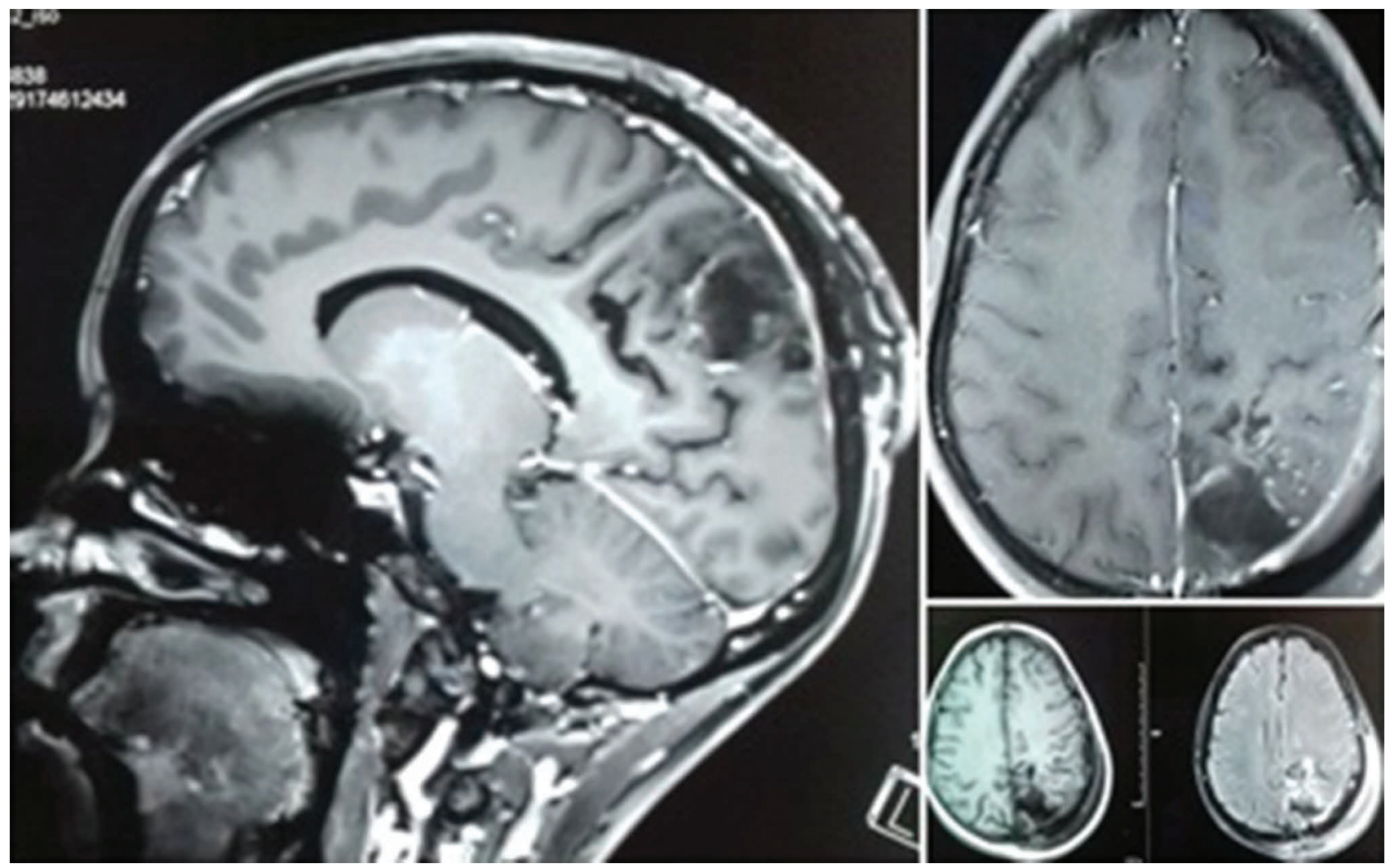

Fig. 3 Magnetic resonance images done at 12-month follow-up showing no evidence of recurrence. 
meningioma, a differential diagnosis is often challenging. Higher signal intensity on T2- and lower on T1-weighted images, absence of edema and dural-tail sign, a peculiar honeycomb pattern of enhancement, and a well-preserved pial barrier around the tumor are important suggestive criteria for chondroid tumors. Pathologic diagnosis is the gold standard, and neurosurgical resection is the mainstay of therapy. Classic chondrosarcomas have a better prognosis compared with myxoid and mesenchymal variants and usually do not require adjuvant treatment modalities as long as surgery allows a radical resection of tumor.

\section{Source of Support}

None.

\section{Conflict of Interest}

None declared.

\section{References}

1 Güneş M, Günaldi O, Tuğcu B, Tanriverdi O, Güler AK, Cöllüoğlu B. Intracranial chondrosarcoma: a case report and review of the literature. Minim Invasive Neurosurg 2009;52(5-6):238-241

2 Alvira MM, McLaurin RL. Asymptomatic subdural chondrosarcoma. Case report. J Neurosurg 1978;48(5):825-828

3 Cybulski GR, Russell EJ, D’Angelo CM, Bailey OT. Falcine chondrosarcoma: case report and literature review. Neurosurgery $1985 ; 16(3): 412-415$
4 Gerszten PC, Pollack IF, Hamilton RL. Primary parafalcine chondrosarcoma in a child. Acta Neuropathol 1998;95(1):111-114

5 Forbes RB, Eljamel MS. Meningeal chondrosarcomas, a review of 31 patients. Br J Neurosurg 1998;12(5):461-464

6 Oruckaptan HH, Berker M, Soylemezoglu F, Ozcan OE. Parafalcine chondrosarcoma: an unusual localization for a classical variant. Case report and review of the literature. Surg Neurol 2001;55(3):174-179

7 Kothary N, Law M, Cha S, Zagzag D. Conventional and perfusion MR imaging of parafalcine chondrosarcoma. AJNR Am J Neuroradiol 2003;24(2):245-248

8 Tosaka M, Fukasawa Y, Takahashi A, Sasaki A, Saito N. Incidentally detected parafalcine chondrosarcoma. Acta Neurochir (Wien) 2005;147(7):795-799, discussion 799

9 Kathiravel Y, Finnis ND. Primary falcine chondrosarcoma. J Clin Neurosci 2008;15(12):1406-1409

10 Boccardo M, Bavaresco E, Sola S, Vitali A. Parafalcine chondrosarcoma: report of a case and review of the literature. J Neurosurg Sci 2009;53(3):137-140

11 Sheth RN, Thompson SN, Morcos JJ. Drop metastasis from primary intracranial mesenchymal chondrosarcoma. Case Rep FRCS Ann Neurosurg 2009;9:1-9

12 Krishnan SS, Panigrahi M, Varma D, Madigubba S. Falcine and parasagittal intracranial chondrosarcomas of the classical variant: report of two cases with review of literature. Neurol India 2011;59(3):451-454

13 Korten AGGC, ter Berg HJW, Spincemaille GH, van der Laan RT, Van de Wel AM. Intracranial chondrosarcoma: review of the literature and report of 15 cases. J Neurol Neurosurg Psychiatry 1998;65(1):88-92 